\title{
Outcomes of Admissions for Preterm Labor
}

\author{
Michael W. Kuzniewicz, MD, MPH ${ }^{1,2,3}$ Libby Black, $\mathrm{PhD}^{4} \quad$ Eileen M. Walsh, RN, MPH ${ }^{1} \quad$ Sherian X. Li, MS ${ }^{1}$ \\ Mara Greenberg, MD ${ }^{5}$
}

${ }^{1}$ Division of Research, Kaiser Permanente Northern California, Oakland, California

2 Division of Neonatology, Kaiser Permanente Northern California, San Francisco, California

${ }^{3}$ Department of Pediatrics, University of California, San Francisco, California

${ }^{4}$ GlaxoSmithKline, Value Evidence and Outcomes, North Carolina

${ }^{5}$ Department of Obstetrics and Gynecology, Kaiser Permanente Northern California, San Francisco, California

\author{
Address for correspondence Michael W. Kuzniewicz, MD, MPH, \\ Division of Research, Perinatal Research Unit, Kaiser Permanente \\ Northern California, 2000 Broadway, Oakland, CA 94612 \\ (e-mail: Michael.W.Kuzniewicz@kp.org).
}

Am J Perinatol Rep 2017;7:e116-e123.

\begin{abstract}
Keywords

- preterm labor

- maternal-fetal medicine

- labor and delivery

- neonatal outcomes

Objective This study aims to quantitate the incidence of preterm labor (PTL) admissions and determine the frequency and predictors of preterm delivery (PTD) during these admissions.

Study Design Retrospective cohort of singleton pregnancies within Kaiser Permanente Northern California, 2001 to 2011. PTL admissions were defined as inpatient encounters $>24$ hours with an International Classification of Diseases, 9th Revision code for PTL.

Results Total study population was 365,897 with PTL admission rate $11 \%$. PTD occurred in $85 \%$ of pregnancies with PTL admission. Delivery occurred within 48 hours of admission in $96 \% \geq 34$ weeks, $67 \% 31$ to 33 weeks, and $51.9 \%<31$ weeks. Predictors of delivery during PTL admission included gestational age 34 to 36 weeks (adjusted odds ratio [aOR], 6.90), chorioamnionitis (aOR, 105.58), and preterm rupture of membranes (aOR 19.29).

Conclusion We demonstrate a high rate of PTD per PTL admission in a highly integrated health care system. More work is needed to determine optimal practices for hospitalization and treatment of women diagnosed with PTL.
\end{abstract}

Preterm birth is associated with increased neonatal mortality and long-term morbidity. ${ }^{1-3}$ Preterm delivery may occur due to maternal or fetal indications, or result from preterm premature rupture of membranes or after spontaneous preterm labor (PTL) with intact membranes. Approximately 32 to $50 \%$ of preterm births are the consequence of spontaneous PTL. ${ }^{4-7}$ The etiology is often multifactorial and poorly understood. Contributory features include hormonal changes, uterine overdistension, cervical disease, infection/inflammation, uteroplacental ischemia/hemorrhage, or immunologic pathology. ${ }^{8,9}$

Substantial variation exists in the diagnosis and management of PTL. ${ }^{10}$ A literature search for guidelines or best practice recommendations for clinicians caring for patients who present with possible PTLyielded no comprehensive algorithm for the management of such patients. Unfortunately, current strategies such as tocolytic agents have shown limited efficacy and are associated with undesirable side effects. ${ }^{11-19}$

Not all women admitted with a diagnosis of PTL delivery prematurely, illustrating that it may be difficult to determine which women have true PTL initially. ${ }^{20,21}$ Determining which women admitted with PTL who are most likely to deliver imminently may be helpful in defining the population most likely to benefit from new interventions or medications to prolong pregnancy. received

March 17, 2017

accepted after revision

May 11, 2017
DOI https://doi.org/

10.1055/s-0037-1603911. ISSN 2157-6998.
Copyright $\odot 2017$ by Thieme Medical

Publishers, Inc., 333 Seventh Avenue, New York, NY 10001, USA. Tel: +1(212) 584-4662.
License terms

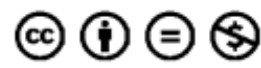


Few population-based studies have examined the outcomes of admissions for PTL. ${ }^{20,22-27}$ The aims of the study were to quantitate the incidence of admissions for PTL, to examine maternal and neonatal outcomes, and evaluate predictors for delivery after PTL admission in a large population-based cohort.

\section{Methods}

\section{Study Population and Design}

We utilized a retrospective cohort design. The study cohort consisted of singleton pregnancies that resulted in a live birth between January 1, 2001 and December 31, 2011, at a Kaiser Permanente Northern California (KPNC) facility. KPNC serves a population of 3.7 million members, which constitutes nearly half of the insured population in Northern California. A total of 16 facilities were included in the study. KPNC facilities share the same common medical record numbers and database systems, which permits linkage of maternal and neonatal records to each other and to multiple information systems (e.g., laboratory and hospitalization data). ${ }^{28}$ We excluded pregnancies with missing infant gestational age at birth, birth weight, or maternal discharge data.

The KPNC Institutional Review Board approved the study.

\section{Classification of Preterm Labor Admissions}

We identified all maternal admissions that occurred between $20^{0 / 7}$ and $36^{6 / 7}$ weeks' gestation from the KPNC virtual data warehouse (VDW). The VDW contains electronic records of all patient encounters (inpatient and outpatient) at KPNC facilities, including health plan enrollment dates, encounter dates with location, dispositions, diagnostic and procedure codes, laboratory tests, and their results. ${ }^{29}$ Gestational age was determined from the maternal record and defined according to the obstetrically assigned estimated date of confinement (EDC). For women with regular menstrual cycles, EDC was based on last menstrual period if in 7-day agreement with a first-trimester ultrasound. For women with irregular menstrual cycles, EDC was determined from first-trimester ultrasound results. We categorized encounters by completed weeks of gestation at admission: $\leq 24,25$ to 27,28 to 30,31 to 33 , and 34 to 36 weeks.

We identified admissions for PTL by selecting inpatient encounters that had an International Disease Classification (ICD-9) code for PTL (644.0, 644.00, 644.03, 644.20, 644.21, V23.41) assigned. Admissions for observation less than 24 hours were not included ( $n=23,282)$. PTL admissions were classified as spontaneous PTL if there were no other complicating diagnoses such as preterm premature rupture of membranes (658.1, $658.10,658.11,658.13)$, chorioamnionitis $(658.4 x)$, preeclampsia/eclampsia $(642.5 \mathrm{x}, 642.6 \mathrm{x}, 642.7 \mathrm{x})$, cervical incompetence $(622.5,654.5 x, 654.6 x)$, or bleeding/placenta previa/abruption (641.1x, 641.2x, 641.3x, 641.8x, 641.9x). We examined these spontaneous PTL admissions separately with the hypothesis that these otherwise uncomplicated pregnancies may have different outcomes than more complicated PTL admissions.

\section{Maternal and Infant Characteristics and Outcomes}

KP administrative databases supplied data on maternal race/ ethnicity, maternal age at delivery, and mode of delivery.
Small for gestational age (SGA) was determined by plotting the infant's weight and gestational age on the Fenton curves, using $<$ fifth percentile as a cutoff for SGA. ${ }^{30}$ Postpartum hemorrhage was determined from discharge diagnosis ICD-9 codes. The KPNC VDW provided data on inpatient, 30-day, and 1-year mortality as well as infant or maternal intensive care unit admission. If a mother required a transfer between $\mathrm{KP}$ facilities, we analyzed the combined hospital stays as a single hospitalization.

\section{Statistical Analysis}

We performed comparisons of characteristics, maternal outcomes, and neonatal outcomes, using chi-square or Fisher's exact test, as appropriate. For PTL admissions, multivariate logistic regression models assessed the association between gestational age at admission, maternal age, and maternal race/ethnicity, additional maternal diagnoses, and the number of admissions and the outcome of delivery. The models included the birth year and facility as covariates, with adjustment for clustering by a woman, as some women had multiple pregnancies.

\section{Results}

We identified 368,068 singleton pregnancies and excluded records missing infant gestational age $(n=1,190)$, birth weight $(n=259)$, or maternal discharge date $(n=722)$. The study cohort consisted of 365,897 pregnancies. At least one preterm inpatient admission occurred in $11 \%$ ( $n=40,291$ ) of pregnancies. Of these admissions, $52 \%$ had a diagnosis of PTL. Thus, $6 \%$ of all pregnancies were complicated by PTL. The majority (55\%) of PTL admissions had no other complications (- Fig. 1).

We compared women with PTL admission to those without a PTL admission (-Table 1). Women with a PTL admission were more likely to be Black, at the extremes of age $(<18$ or $\geq 40$ ), and to have another pregnancy complication. These women were also more likely to deliver by cesarean section and to have infants that were SGA or had a congenital anomaly.

Overall, 85\% of pregnancies with PTL admissions resulted in the delivery of a preterm infant. The proportion was higher for complicated PTL (93\%) compared with spontaneous PTL (79\%), $p<.0001$. We examined the time to delivery from first PTL admission, stratified by gestational age at admission ( - Fig. 2 ). The delivery curves were similar for all PTL admissions and spontaneous PTL admissions. Time to delivery differed substantially depending on gestational age at admission. For PTL admissions $\geq 34$ weeks, delivery occurred within 48 hours in $96 \%$ of the admissions. For infants 31 to 33 weeks, $67 \%$ delivered before 48 hours. Infants admitted $<31$ weeks showed similar delivery curves, with $51.9 \%$ delivering within 48 hours and $77.6 \%$ within 7 days after admission.

Maternal and infant outcomes of pregnancies with a PTL admission were significantly worse than pregnancies without a PTL admission. There were elevated rates of maternal intensive care unit admission, inpatient maternal mortality, and 30-day maternal mortality. As expected, with a higher rate of preterm delivery, neonatal intensive care unit admissions, inpatient infant mortality, and 1-year mortality were also 


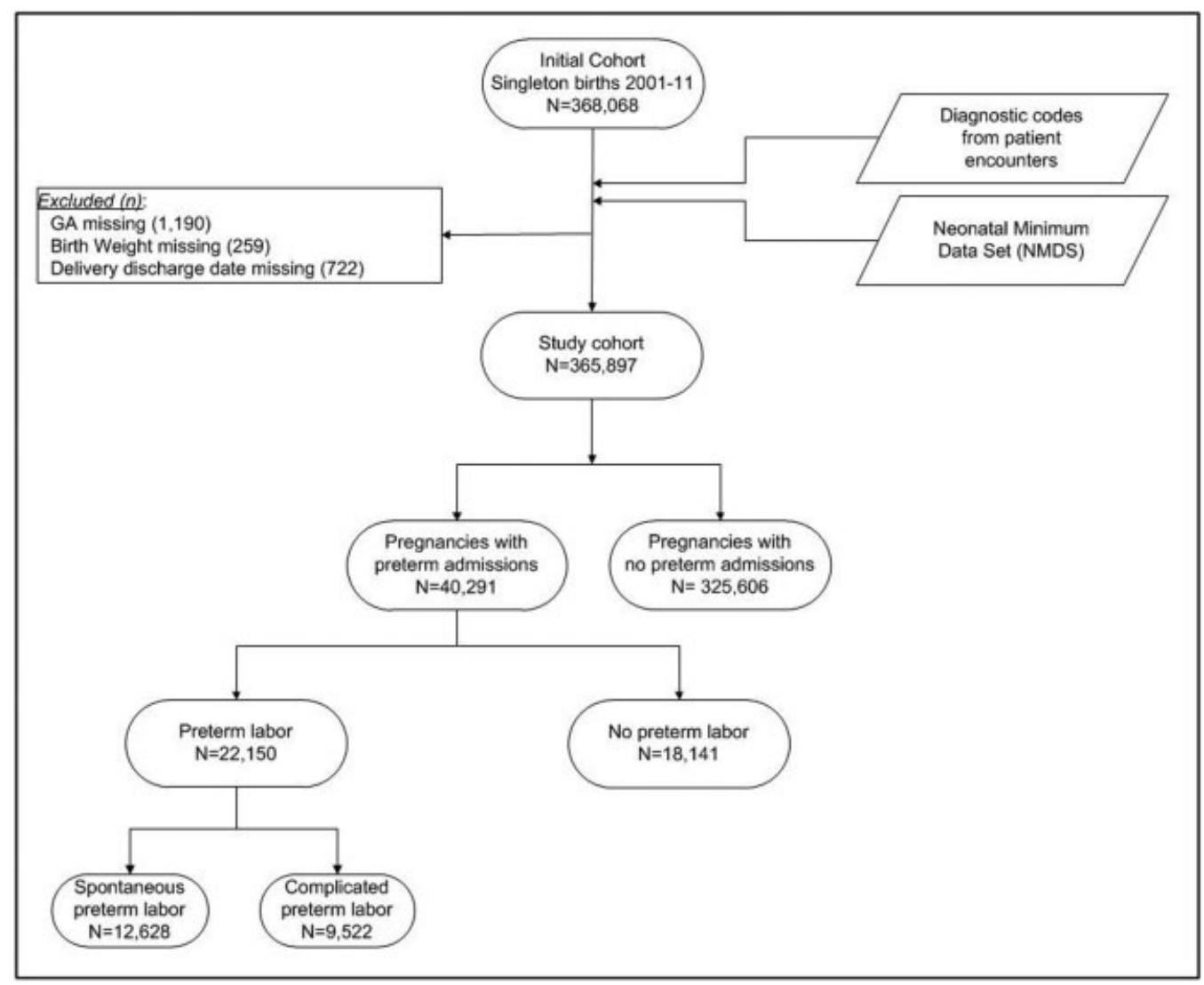

Fig. 1 Study population.

higher. These differences persisted even in the spontaneous PTL subset (-Table 2).

We evaluated predictors for delivery using multivariate logistic regression in the PTL admission cohort (- Table 3 ). Admissions at 34 to 36 weeks were strongly associated with delivery. Compared with admission at 31 to 33 , all gestational groups $<31$ weeks were statistically less likely to deliver during the admission. Women older than 34 years were more likely to have an admission that resulted in delivery than women younger than 30 years. Diagnoses of chorioamnionitis or preterm premature rupture of membranes (PPROM) was strong predictors of delivering during that admission. Placental abruption/previa also increased the risk of delivering but to a lesser degree. If an admission was the first preterm admission for the mother, there was a reduced risk of delivery, compared with subsequent preterm admissions. Restricting the analysis to spontaneous PTL showed similar results

\section{Discussion}

This population-based study shows that $11 \%$ of singleton pregnancies result in at least one preterm admission. Over half of preterm admissions related to a diagnosis of PTL, of which over half are uncomplicated. A population-based study from New South Wales, Australia (2001-2008) showed that $4.2 \%(28,796 / 688,902)$ of singleton pregnancies were admitted with a diagnosis of PTL between 20 and 36 weeks gestation, ${ }^{20}$ similar to our results in which there were $5.6 \%$ of singleton pregnancies with at least one admission for PTL.

Of the pregnancies with at least one PTL admission, 85.0\% delivered preterm. Our data demonstrate that the majority of women who deliver during PTL admission have a short latency between time of admission and time of delivery despite presumptive receipt of tocolytics and other standard interventions in use at KPNC, consistent with prior studies demonstrating a lack of substantial pregnancy prolongation with interventions such as tocolysis. ${ }^{10,11,14-16}$

When latency is shorter, there may be insufficient time to enable the maximal benefit of antenatal steroids, which have been proven to accelerate fetal lung maturity, and are most effective when administered at least 48 hours before delivery. ${ }^{31-33}$ It appears current strategies are failing to have a significant impact on prolonging pregnancy in women with PTL. Unfortunately, this leads to worse neonatal outcomes. Numerous studies have documented the benefit of each additional week of gestational age on neonatal morbidity and mortality. ${ }^{34}$

Older studies have suggested that over half of the women diagnosed with PTL will deliver at term. ${ }^{24,25}$ Our study shows this percentage to be much lower. In our study, $15.1 \%$ of mothers admitted for PTL ultimately delivered at term. The higher delivery rate after PTL admission in our study may be explained by more selective admission of patients with suspected PTL. In KPNC, more patients with suspected PTL 
Table 1 Characteristics and outcomes of mothers with at least one PTL admission, compared with mothers with no PTL admission

\begin{tabular}{|c|c|c|c|c|c|}
\hline \multirow[t]{2}{*}{ Characteristic } & \multicolumn{2}{|c|}{$\begin{array}{l}\text { PTL admission } \\
(n=22,150)\end{array}$} & \multicolumn{2}{|c|}{$\begin{array}{l}\text { No PTL admission } \\
(n=343,747)\end{array}$} & \multirow[t]{2}{*}{$p$ Value } \\
\hline & $n$ & $\%$ & $n$ & $\%$ & \\
\hline \multicolumn{6}{|l|}{ Race/ethnicity } \\
\hline White & 8,087 & 36.5 & 138,101 & 40.2 & \multirow[t]{5}{*}{$<0.0001$} \\
\hline Black & 2,420 & 10.9 & 25,996 & 7.6 & \\
\hline Asian & 4,946 & 22.3 & 74,567 & 21.7 & \\
\hline Hispanic & 5,286 & 23.9 & 86,717 & 25.2 & \\
\hline Other/unknown & 1,411 & 6.4 & 18,366 & 5.3 & \\
\hline \multicolumn{6}{|l|}{ Maternal age $(\mathrm{y})$} \\
\hline$<18$ & 477 & 2.2 & 4,526 & 1.3 & \multirow[t]{4}{*}{$<0.0001$} \\
\hline $18-29$ & 9,995 & 45.1 & 155,830 & 45.3 & \\
\hline $30-39$ & 10,426 & 47.1 & 167,142 & 48.6 & \\
\hline $40+$ & 1,252 & 5.7 & 16,249 & 4.7 & \\
\hline More than one preterm admission & 3,339 & 15.1 & 1,162 & 0.3 & $<0.0001$ \\
\hline No major pregnancy complications ${ }^{\mathrm{a}}$ & 12,038 & 54.4 & 296,170 & 86.2 & $<0.0001$ \\
\hline Maternal diabetes & 3,642 & 16.4 & 34,062 & 9.9 & $<0.0001$ \\
\hline Preterm rupture of membranes & 4,310 & 19.5 & 18,948 & 5.5 & $<0.0001$ \\
\hline Chorioamnionitis & 1,470 & 6.6 & 19,781 & 5.8 & $<0.0001$ \\
\hline Hypertension/preeclampsia & 2,855 & 12.9 & 6,529 & 1.9 & $<0.0001$ \\
\hline Incompetent cervix & 776 & 3.5 & 1,578 & 0.5 & $<0.0001$ \\
\hline Placental abruption or previa & 2,177 & 9.8 & 4,033 & 1.2 & $<0.0001$ \\
\hline \multicolumn{6}{|l|}{ Delivery mode } \\
\hline Cesarean & 7,444 & 33.6 & 80,542 & 23.4 & \multirow[t]{2}{*}{$<0.0001$} \\
\hline Vaginal & 14,656 & 66.2 & 262,667 & 76.4 & \\
\hline Preterm ( $<37 \mathrm{wk}$ ) delivery & 18,816 & 85.0 & 5,698 & 1.7 & $<0.0001$ \\
\hline Infant small for gestational age & 685 & 3.1 & 5,713 & 1.7 & $<0.0001$ \\
\hline Major congenital anomaly & 1,299 & 5.9 & 4,459 & 1.3 & $<0.0001$ \\
\hline
\end{tabular}

Abbreviation: PTL, preterm labor.

${ }^{a}$ No diagnosis of premature rupture of membranes, chorioamnionitis, hypertension/preeclampsia, incompetent cervix, placental abruption/previa.

${ }^{\mathrm{b}}$ Major anomalies include cardiovascular, chromosomal, central nervous system, gastrointestinal, urinary tract.

may be evaluated and monitored in outpatient settings, due to the robust integration of services. What is unclear in these cases of nondelivery after PTL admission is whether they represent the successful resolution of preterm labor or an incorrect assignment of a diagnostic code for PTL. Since our study was retrospective and relied on administrative data, the specific clinical data required to classify true PTL were not available.

A small prospective study $(n=234)$ from North Carolina showed a delivery rate after PTL admission of 38.5\%; however, when PTL was diagnosed at $<33$ weeks, the delivery rate was $17.1 \%$, and when diagnosed at $\geq 33$ weeks, the rate was $64.8 \%{ }^{35}$ Our data also shows that delivery rates differ by gestational age at admission. As a result, caution must be taken in comparing the delivery rate after PTL across studies, as gestational age at presentation has a significant impact on the rates.
Examining the predictors of delivery during PTL admission, later gestational age at presentation (34-36 weeks) was a strong predictor. The higher delivery rate and short latency periods in admissions $\geq 34$ weeks may reflect decreased efforts on behalf of the obstetricians to prolong labor. The American College of Obstetricians and Gynecologists (ACOG) does not currently recommend the use of tocolytics after 34 weeks given their limited efficacy, side effects, and reduced neonatal morbidity, and mortality at this gestational age. ${ }^{36}$ However, if effective and safe interventions were available, there may be utility in treating PTL at this later gestational age, since late preterm infants have increased morbidity compared with term infants. ${ }^{37-42}$ Alternatively, the lower rate of delivery per preterm admission seen earlier in the third trimester may represent a lower threshold to admit for suspected PTL at earlier gestational ages, resulting in a higher false-positive rate of PTL diagnosis in this subgroup. 


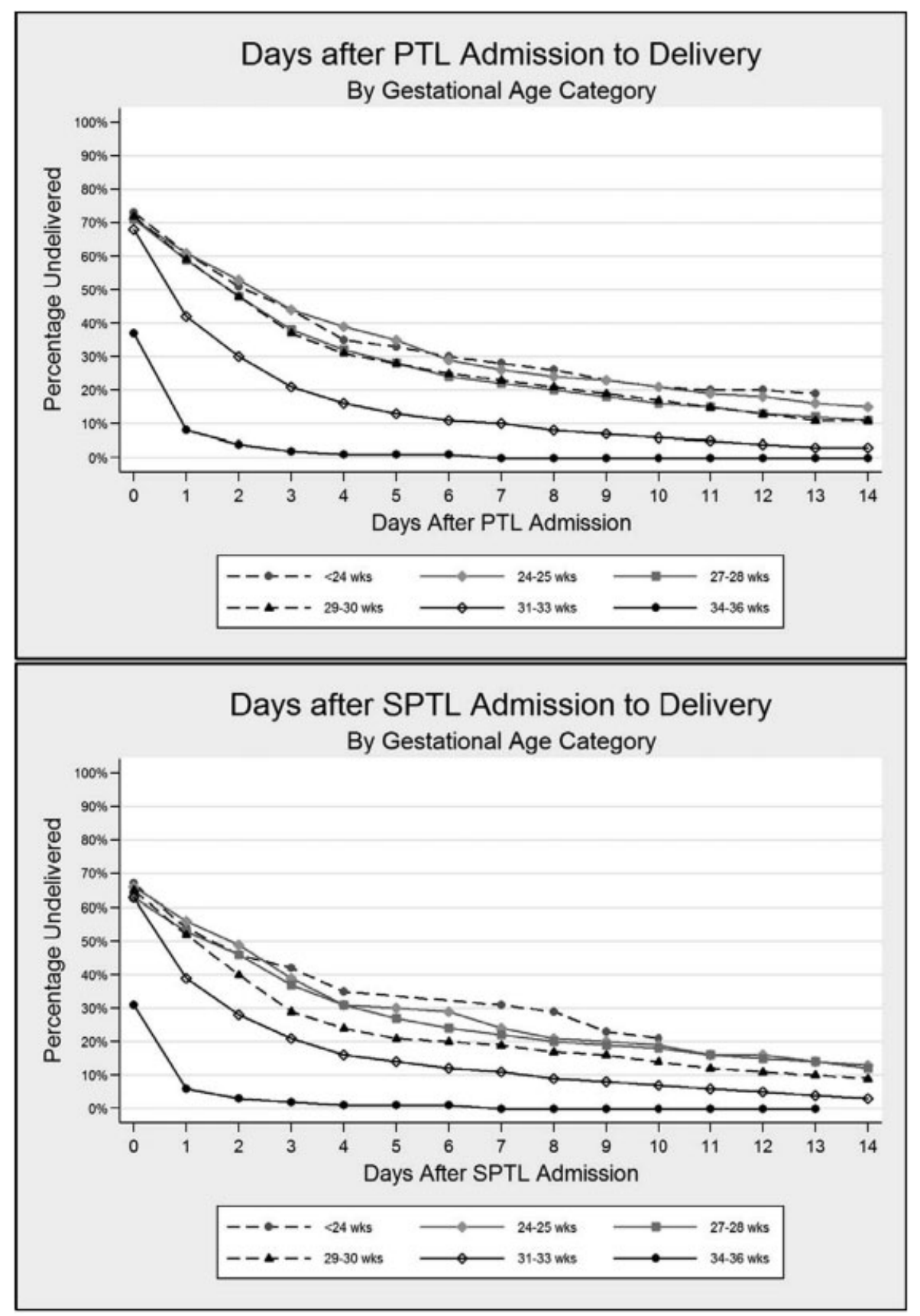

Fig. 2 Days from PTL admission to delivery, all PTL, and spontaneous PTL. PTL, preterm labor.

The main limitation of our study was reliance on administrative data to define PTL. Most past studies have this same limitation. A large number of patients in this populationbased study made it impractical to perform chart review on all PTL admissions to confirm the diagnosis. While some of our PTL admissions may not have met clinical criteria, the finding of a higher delivery rate after PTL admission than prior studies may suggest that we had fewer inclusions of false labor in our PTL admissions than other studies.

In our study, we also do not have data on the interventions the women received while admitted for PTL in terms of tocolytics, fluids, etc. As a result, we do not have the ability to differentiate if one treatment or management strategy was superior in prolonging the time to delivery. However, such questions are better answered using randomized controlled trials. We were also unable to detangle the temporal relationship between PTL, PPROM, and chorioamnionitis.

Given the short latency and high delivery rate after PTL admission, a better understanding of the regulation of myometrial contractility is still needed. Development of agents that target the process leading to myometrial activation may prove to be more effective in prolonging time to delivery, providing additional time for fetal maturation as well as an expanded timeframe for clinical interventions (steroids, magnesium, and antibiotics) known to improve maternal and infant outcomes. 
Table 2 Maternal and infant outcomes, pregnancies with all PTL and spontaneous PTL, compared with pregnancies with no PTL

\begin{tabular}{|c|c|c|c|c|c|c|}
\hline & \multicolumn{2}{|c|}{$\begin{array}{l}\text { All PTL } \\
(n=22,150)\end{array}$} & \multicolumn{2}{|c|}{$\begin{array}{l}\text { Spontaneous PTL } \\
(n=12,628)\end{array}$} & \multicolumn{2}{|c|}{$\begin{array}{l}\text { No PTL } \\
(n=343,747)\end{array}$} \\
\hline & $n$ & $\%$ & $n$ & $\%$ & $n$ & $\%$ \\
\hline \multicolumn{7}{|l|}{ Maternal outcomes } \\
\hline Postpartum hemorrhage & 517 & 2.3 & 284 & 2.2 & 8,434 & 2.5 \\
\hline ICU admission & 134 & $0.6^{\mathrm{a}}$ & 36 & $0.3^{b}$ & 467 & 0.1 \\
\hline Inpatient mortality & 6 & $0.0^{\mathrm{a}}$ & 3 & $0.0^{\mathrm{b}}$ & 6 & 0.0 \\
\hline 30-d mortality & 12 & $0.1^{\mathrm{a}}$ & 7 & $0.1^{\mathrm{b}}$ & 14 & 0.0 \\
\hline \multicolumn{7}{|l|}{ Infant outcomes } \\
\hline Level-3 NICU admission & 10,089 & 45.5 & 4,318 & $34.2^{\mathrm{b}}$ & 19,623 & 5.7 \\
\hline SGA (<fifth percentile) & 685 & 3.1 & 351 & $2.8^{\mathrm{b}}$ & 5,713 & 1.7 \\
\hline Inpatient mortality & 442 & $2.0^{\mathrm{a}}$ & 185 & $1.5^{\mathrm{b}}$ & 245 & 0.1 \\
\hline One-year mortality & 468 & $2.1^{\mathrm{a}}$ & 200 & $1.6^{\mathrm{b}}$ & 411 & 0.1 \\
\hline
\end{tabular}

Abbreviations: ICU, intensive care unit; NICU, neonatal intensive care unit; PTL, preterm labor; SGA, small for gestational age. ${ }^{a} p<0.001$ (All PTL compared with No PTL).

${ }^{\mathrm{b}} \mathrm{p}<0.001$ (Spontaneous PTL compared with No PTL).

Table 3 aOR for delivery during PTL admission

\begin{tabular}{|c|c|c|c|c|c|c|}
\hline & \multicolumn{3}{|c|}{$\begin{array}{l}\text { All PTL admissions } \\
(n=23,919)\end{array}$} & \multicolumn{3}{|c|}{ Spontaneous PTL admissions $(n=13,678)$} \\
\hline & $\mathrm{aOR}^{\mathrm{a}}$ & $95 \% \mathrm{Cl}$ & $p$ & $\mathrm{aOR}^{\mathrm{a}}$ & $95 \% \mathrm{Cl}$ & $p$ \\
\hline \multicolumn{7}{|l|}{ GA at admission (wk) } \\
\hline$<24$ & 0.54 & $0.41-0.69$ & $<0.0001$ & 0.71 & $0.49-1.03$ & 0.0716 \\
\hline $24-25$ & 0.72 & $0.60-0.87$ & 0.0005 & 0.72 & $0.56-0.93$ & 0.0106 \\
\hline $26-28$ & 0.70 & $0.63-0.81$ & $<0.0001$ & 0.70 & $0.59-0.84$ & $<0.0001$ \\
\hline $29-30$ & 0.71 & $0.63-0.81$ & $<0.0001$ & 0.66 & $0.56-0.77$ & $<0.0001$ \\
\hline $31-33$ & Reference & & & Reference & & \\
\hline $34-36$ & 6.90 & $6.29-7.57$ & $<0.0001$ & 8.68 & $7.81-9.66$ & $<0.0001$ \\
\hline \multicolumn{7}{|l|}{ Maternal age $(\mathrm{y})$} \\
\hline$<18$ & 0.64 & $0.50-0.83$ & 0.0005 & 0.65 & $0.49-0.86$ & 0.0042 \\
\hline $18-24$ & 0.84 & $0.75-0.95$ & 0.0035 & 0.86 & $0.75-0.98$ & 0.0241 \\
\hline $25-29$ & 0.83 & $0.75-0.92$ & 0.0005 & 0.83 & $0.73-0.93$ & 0.0045 \\
\hline $30-34$ & Reference & & & Reference & & \\
\hline $35-39$ & 1.18 & $1.05-1.33$ & 0.0052 & 1.20 & $1.04-1.38$ & 0.0138 \\
\hline $40+$ & 1.49 & $1.23-1.80$ & $<0.0001$ & 1.43 & $1.13-1.81$ & 0.0045 \\
\hline \multicolumn{7}{|l|}{ Maternal race/ethnicity } \\
\hline White & Reference & & & Reference & & \\
\hline Black & 1.06 & $0.92-1.21$ & 0.4273 & 0.96 & $0.82-1.13$ & 0.6554 \\
\hline Asian & 0.99 & $0.89-1.10$ & 0.8204 & 1.07 & $0.94-1.21$ & 0.3304 \\
\hline Hispanic & 1.08 & $0.98-1.20$ & 0.1301 & 1.11 & $0.99-1.26$ & 0.0928 \\
\hline Other/unknown & 1.71 & $1.40-2.08$ & $<.0001$ & 1.83 & $1.48-2.28$ & $<0.0001$ \\
\hline \multicolumn{7}{|l|}{ Clinical characteristics } \\
\hline Chorioamnionitis & 105.58 & $52.30-213.17$ & $<0.0001$ & $\mathrm{~N} / \mathrm{A}$ & N/A & N/A \\
\hline Preterm rupture of membranes & 19.29 & $14.91-24.96$ & $<0.0001$ & $\mathrm{~N} / \mathrm{A}$ & N/A & N/A \\
\hline Incompetent cervix & 0.61 & $0.50-0.74$ & $<0.0001$ & $\mathrm{~N} / \mathrm{A}$ & $\mathrm{N} / \mathrm{A}$ & N/A \\
\hline Placental abruption/previa & 1.75 & $1.53-2.00$ & $<0.0001$ & $\mathrm{~N} / \mathrm{A}$ & N/A & $\mathrm{N} / \mathrm{A}$ \\
\hline First preterm admission & 0.78 & $0.69-0.87$ & $<0.0001$ & 0.84 & $0.73-0.97$ & 0.0282 \\
\hline
\end{tabular}

Abbreviations: aOR, adjusted odds ratio; $\mathrm{Cl}$, confidence interval; GA, gestational age; N/A, not applicable; PTL, preterm labor.

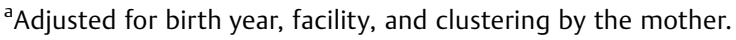


In summary, in a contemporaneous, diverse patient population in a highly integrated health care system, we demonstrate a high rate of preterm delivery per PTL admission. Factors associated with a short latency to delivery included later gestational age and presence of comorbid conditions, such as chorioamnionitis and PPROM. How can we make clinical use of this data? On the one hand, our high rate of preterm delivery per PTL admission represents an appropriate use of inpatient services, and further characterization of our practices may serve as a good model for systems with a higher false-positive rate per PTL admission. On the other hand, it does indicate that any interventions applied to the hospitalized patient at risk of preterm delivery within our health care system infrequently result in substantial pregnancy prolongation. This is reflective of previously published data detailing the lack of efficacy of pharmacologic and nonpharmacological strategies to prolong pregnancy in the setting of PTL and reinforces the need for further development of such strategies.

\section{Authors' Contribution}

1. M.K. discloses grants from GlaxoSmithKline during the conduct of this study.

2. L.B. reports personal fees from GlaxoSmithKline during the conduct of this study and outside the submitted work.

3. E.W., S.L., and M.G. report grants from GlaxoSmithKline during the conduct of this study.

\section{Acknowledgments}

GlaxoSmithKline (GSK) funded the analyses reported in this study under grant number GHO-11-3804. GSK did not compensate the authors for the preparation of this publication.

\section{References}

1 Johnson S, Evans TA, Draper ES, et al. Neurodevelopmental outcomes following late and moderate prematurity: a populationbased cohort study. Arch Dis Child Fetal Neonatal Ed 2015; 100(04):F301-F308

2 Moore T, Hennessy EM, Myles J, et al. Neurological and developmental outcome in extremely preterm children born in England in 1995 and 2006: the EPICure studies. BMJ 2012;345:e7961

3 Callaghan WM, MacDorman MF, Rasmussen SA, Qin C, Lackritz EM. The contribution of preterm birth to infant mortality rates in the United States. Pediatrics 2006;118(04):1566-1573

4 Goldenberg RL, Culhane JF, Iams JD, Romero R. Epidemiology and causes of preterm birth. Lancet 2008;371(9606):75-84

5 Tucker JM, Goldenberg RL, Davis RO, Copper RL, Winkler CL, Hauth JC. Etiologies of preterm birth in an indigent population: is prevention a logical expectation? Obstet Gynecol 1991;77(03):343-347

6 Henderson JJ, McWilliam OA, Newnham JP, Pennell CE. Preterm birth aetiology 2004-2008. Maternal factors associated with three phenotypes: spontaneous preterm labour, preterm pre-labour rupture of membranes and medically indicated preterm birth. J Matern Fetal Neonatal Med 2012;25(06):642-647

7 Moutquin JM. Classification and heterogeneity of preterm birth. BJOG 2003;110(Suppl 20):30-33

8 Romero R, Espinoza J, Kusanovic JP, et al. The preterm parturition syndrome. BJOG 2006;113(Suppl 3):17-42
9 Gotsch F, Gotsch F, Romero R, et al. The preterm parturition syndrome and its implications for understanding the biology, risk assessment, diagnosis, treatment and prevention of preterm birth. J Matern Fetal Neonatal Med 2009;22(02, Suppl 2):5-23

10 Di Renzo GC, Roura LC; European Association of Perinatal Medicine-Study Group on Preterm Birth. Guidelines for the management of spontaneous preterm labor. J Perinat Med 2006;34(05): 359-366

11 Berkman ND, Thorp JM Jr, Lohr KN, et al. Tocolytic treatment for the management of preterm labor: a review of the evidence. Am J Obstet Gynecol 2003;188(06):1648-1659

12 Duckitt K, Thornton S, O’Donovan OP, Dowswell T. Nitric oxide donors for treating preterm labour. Cochrane Database Syst Rev 2014;5(05):CD002860

13 Flenady V, Reinebrant HE, Liley HG, Tambimuttu EG, Papatsonis DN. Oxytocin receptor antagonists for inhibiting preterm labour. Cochrane Database Syst Rev 2014;6(06):CD004452

14 Han S, Crowther CA, Moore V. Magnesium maintenance therapy for preventing preterm birth after threatened preterm labour. Cochrane Database Syst Rev 2010;(07):CD000940

15 King J, Flenady V, Cole S, Thornton S. Cyclo-oxygenase (COX) inhibitors for treating preterm labour. Cochrane Database Syst Rev 2005;(02):CD001992

16 Lamont RF. The development and introduction of anti-oxytocic tocolytics. BJOG 2003;110(Suppl 20):108-112

17 Neilson JP, West HM, Dowswell T. Betamimetics for inhibiting preterm labour. Cochrane Database Syst Rev 2014;2(02):CD004352

18 Hösli I, Sperschneider C, Drack G, Zimmermann R, Surbek D, Irion 0 ; Swiss Society of Obstetrics and Gynecology. Tocolysis for preterm labor: expert opinion. Arch Gynecol Obstet 2014; 289(04):903-909

19 van Vliet EO, Boormans EM, de Lange TS, Mol BW, Oudijk MA. Preterm labor: current pharmacotherapy options for tocolysis. Expert Opin Pharmacother 2014;15(06):787-797

20 Badgery-Parker T, Ford JB, Jenkins MG, Morris JM, Roberts CL. Patterns and outcomes of preterm hospital admissions during pregnancy in NSW, 2001-2008. Med J Aust 2012;196(04):261-265

21 Fuchs IB, Henrich W, Osthues K, Dudenhausen JW. Sonographic cervical length in singleton pregnancies with intact membranes presenting with threatened preterm labor. Ultrasound Obstet Gynecol 2004;24(05):554-557

22 Adams MM, Harlass FE, Sarno AP, Read JA, Rawlings JS. Antenatal hospitalization among enlisted servicewomen, 1987-1990. Obstet Gynecol 1994;84(01):35-39

23 Bacak SJ, Callaghan WM, Dietz PM, Crouse C. Pregnancy-associated hospitalizations in the United States, 1999-2000. Am J Obstet Gynecol 2005;192(02):592-597

24 Scott CL, Chavez GF, Atrash HK, Taylor DJ, Shah RS, Rowley D. Hospitalizations for severe complications of pregnancy, 19871992. Obstet Gynecol 1997;90(02):225-229

25 Gazmararian JA, Petersen R, Jamieson DJ, et al. Hospitalizations during pregnancy among managed care enrollees. Obstet Gynecol 2002;100(01):94-100

26 Adelson PL, Child AG, Giles WB, Henderson-Smart DJ. Antenatal hospitalisations in New South Wales, 1995-96. Med J Aust 1999; 170(05):211-215

27 Liu S, Heaman M, Sauve R, et al; Maternal Health Study Group of the Canadian Perinatal Surveillance System. An analysis of antenatal hospitalization in Canada, 1991-2003. Matern Child Health J 2007;11(02):181-187

28 Escobar GJ, Fischer A, Kremers R, Usatin MS, Macedo AM, Gardner MN. Rapid retrieval of neonatal outcomes data: the Kaiser Permanente Neonatal Minimum Data Set. Qual Manag Health Care 1997;5(04):19-33

29 Chimmula S, Dhuru R, Folck B, et al. PS2-44: VDW data sources: Kaiser Permanente Northern California. Clin Med Res 2012; 10(03):193 
30 Fenton TR. A new growth chart for preterm babies: Babson and Benda's chart updated with recent data and a new format. BMC Pediatr 2003;3:13

31 Liggins GC, Howie RN. A controlled trial of antepartum glucocorticoid treatment for prevention of the respiratory distress syndrome in premature infants. Pediatrics 1972;50(04):515-525

32 NIH Consensus Development Panel on the Effect of Corticosteroids for Fetal Maturation on Perinatal Outcomes. Effect of corticosteroids for fetal maturation on perinatal outcomes. JAMA 1995;273(05):413-418

33 Crowley P, Chalmers I, Keirse MJ. The effects of corticosteroid administration before preterm delivery: an overview of the evidence from controlled trials. Br J Obstet Gynaecol 1990;97 (01):11-25

34 Tyson JE, Parikh NA, Langer J, Green C, Higgins RD; National Institute of Child Health and Human Development Neonatal Research Network. Intensive care for extreme prematurity-moving beyond gestational age. N Engl J Med 2008;358(16):1672-1681

35 McPheeters ML, Miller WC, Hartmann KE, et al. The epidemiology of threatened preterm labor: a prospective cohort study. Am J Obstet Gynecol 2005;192(04):1325-1329, discussion 1329-1330

36 American College of Obstetricians and Gynecologists; Committee on Practice Bulletins-Obstetrics. ACOG practice bulletin no. 127:
Management of preterm labor. Obstet Gynecol 2012;119(06): 1308-1317

37 Escobar GJ, Clark RH, Greene JD. Short-term outcomes of infants born at 35 and 36 weeks gestation: we need to ask more questions. Semin Perinatol 2006;30(01):28-33

38 Kuzniewicz MW, Parker SJ, Schnake-Mahl A, Escobar GJ. Hospital readmissions and emergency department visits in moderate preterm, late preterm, and early term infants. Clin Perinatol 2013;40(04):753-775

39 Escobar GJ, McCormick MC, Zupancic JA, et al. Unstudied infants: outcomes of moderately premature infants in the neonatal intensive care unit. Arch Dis Child Fetal Neonatal Ed 2006;91(04): F238-F244

40 Kramer MS, Demissie K, Yang H, Platt RW, Sauvé R, Liston R; Fetal and Infant Health Study Group of the Canadian Perinatal Surveillance System. The contribution of mild and moderate preterm birth to infant mortality. JAMA 2000;284(07):843-849

41 McIntire DD, Leveno KJ. Neonatal mortality and morbidity rates in late preterm births compared with births at term. Obstet Gynecol 2008;111(01):35-41

42 Melamed N, Klinger G, Tenenbaum-Gavish K, et al. Short-term neonatal outcome in low-risk, spontaneous, singleton, late preterm deliveries. Obstet Gynecol 2009;114(2 Pt 1):253-260 